\title{
Monitoring the effectiveness of personalized metabolic correction in athletes using biocrystallomics techniques
}

\author{
Andrew K. Martusevich ${ }^{1,3}$, Konstantin A. Karuzin², Ivan V. Bocharin ${ }^{3}$, Alexandra V. Surovegina ${ }^{3}$ \\ ${ }^{1}$ N.I. Lobachevsky Nizhny Novgorod State University, Russia \\ ${ }^{2}$ Bioniq Health-Tech Solutions Ltd., London, Great Britain, \\ ${ }^{3}$ Privolzhsky Research Medical University, Nizhny Novgorod, Russia,
}

Received: June 4, 2021. Revised: December 20, 2021. Accepted: January 14, 2022. Published: January 21, 2022

\begin{abstract}
The aim of this study was to estimate the effect of personalized metabolic support on the character of dehydration structuring of blood serum of qualified athletes. The study included 55 athletes with the category of cyclical sports. The random number test subjects were divided into 2 groups: the main group $(n=23)$, where individualized metabolic correction was performed, and the comparison group $(n=22)$, whose received placebo. Blood samples were obtained from athletes of both groups before the course and immediately after its completion. Then micro-preparations were prepared using the technology of classical crystalloscopy. Crystalloscopic facias were estimated with own system of visuamitric parameters. The study allowed us to establish that in qualified athletes, the course of taking biologically active agents, individualized on the basis of a multiparametric assessment of the state of oxidative metabolism of blood, contributed to the optimization of the crystallogenic properties of blood serum. This was manifested in the transformation of the structure of the main elements of the picture in the direction of reducing their size with a proportional increase in density, as well as in reducing the degree of destruction of crystals and expanding the marginal zone of the micropreparation.
\end{abstract}

Keywords-athletes, metabolism, biocrystallomics, crystallogenic properties, blood serum

\section{INTRODUCTION}

$\mathrm{I}$ $\mathrm{t}$ is known that intensive physical training and high competitive activity, characteristic of highly qualified athletes, contribute to the emergence of various dysregulatory pathologies in the latter [1], [2]. This is manifested in the formation of shifts in the functional state of the cardiovascular system and parameters of cell and tissue metabolism [3], [4], [5]. This trend fully applies to oxidative metabolism, providing in some cases the formation of oxidative stress of varying severity [6], [7]. In our previous studies, we also obtained evidence of a violation of the balance of pro-and antioxidant systems of the blood in qualified (professional) athletes, which consisted in a marked increase in the intensity of lipid peroxidation of blood plasma against the background of inhibition of the latter's antioxidant potential [2], [5], [8]-[12]. This determines the need for targeted correction of these metabolic shifts in the athletes' body.

Currently, the methods of biocrystallomics as new biomedical science are considered as an informative indicator of the physical and chemical properties of biological substrates of the human body [13], [14]. They allow you to indirectly assess both the current state of metabolism and its dynamics [13][15].

The purpose of the study was to estimate the effect of personalized metabolic support on the character of dehydration structuring of blood serum of qualified athletes.

\section{MATERIAL AND METHODS}

The study included 55 athletes with the category of cyclical sports. The random number test subjects were divided into 2 groups: the main group $(\mathrm{n}=23)$, where individualized metabolic correction was performed, and the comparison group $(n=22)$, whose received placebo. The research was carried out during the training period.

A wide range of parameters of oxidative metabolism (superoxide dismutase and glutathione peroxidase activity, glutathione concentration, total antioxidant activity, fatty acid level, etc.) of blood plasma and red blood cells were evaluated for the correct selection of the composition of the metabolic correction agent in the main group. Based on the results of this test, a composition for metabolic support was made individually [3]. The duration of the course of daily use of this composition was similar to the duration of placebo intake by the subjects of the comparison group and was 1 month.

Blood samples were obtained from athletes of both groups before the course and immediately after its completion. Plasma was extracted from blood samples by standard centrifugation. 
Then micro-preparations were prepared using the technology of classical crystalloscopy [14]. The results of dehydration structuring of biological fluid were described using a proprietary system of semi-quantitative parameters. Visuametric indicators evaluated in point scale, were crystallizability (reflects quantity of the crystallization density of the crystalline elements in facias), structure index (characterized by the complexity of structure), the facia destruction degree (provides an indicator of the qualitative side of the process) and the severity of regional zones of microslides [14].

The obtained data was processed statistically in the software package Statistica 6.1 for Windows. The normality of the distribution of parameter values was evaluated using the Shapiro-Wilk test. Taking into account the nature of the attribute distribution, the Student t-test was used to assess the statistical significance of differences. The critical level of significance for testing statistical hypotheses in this study was assumed to be 0.05 .

\section{RESULTS AND DISCUSSION}

It was found that initially the athletes included in the main group and the comparison group were absolutely comparable in all evaluation indicators, without showing statistically significant differences (Fig. 1-4).

At the same time, the further dynamics of the crystallogenic properties of blood serum in the representatives of the formed groups is not the same. Thus, the subjects who received placebo, at the end of the course of taking the latter, did not show significant deviations from the original picture of the structure of the biological fluid (Fig. 1-4).

On the contrary, when using individualized metabolic correction, changes in the level of all controlled parameters of the dehydration structuring of the biological medium were registered. In particular, the study course contributed to a significant shift in the nature of crystallization towards the formation of smaller, single-crystal elements, which increased the density of their distribution in the micro-product. This caused an increase in crystallizability in combination with a corresponding decrease in the structural index (Fig. 1 and 2). These trends were statistically significant $(p<0.05$ for both parameters relative to the first control point of the study).

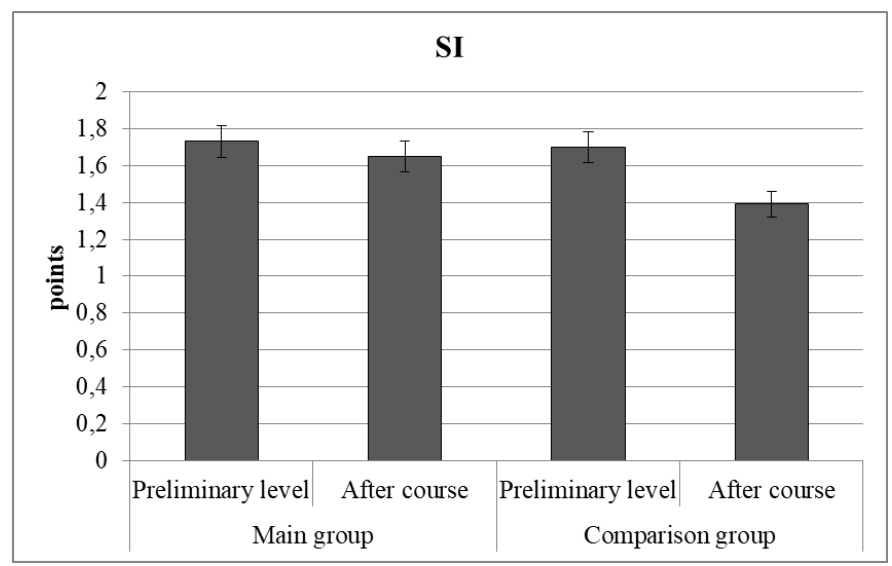

Figure 1. Structure index in facias of athletes blood serum during the administration of personalized vitamin and mineral complex $\left(\left\langle^{*}\right\rangle\right)$ - statistical value of differences to preliminary level is $\mathrm{p}<0.05$ )

Similar features were recorded for the main indicator of the correctness of crystallogenesis - the facia destruction degree (Fig. 3). It is important to emphasize that initially, the athletes of both groups were found to have sufficiently high values of this parameter, reaching an average degree of destruction of the structural elements of the picture. At the end of the course of placebo administration, the comparison group observed only a minimal decrease in the value of this parameter (at the level of statistical trend; $\mathrm{p}=0.089$ relative to the initial state).

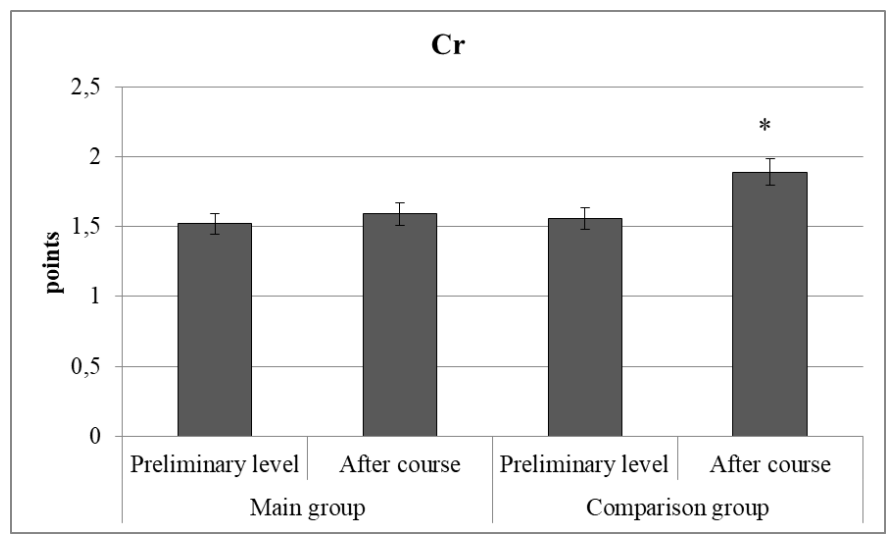

Figure 2. Crystalliability level in facias of athletes blood serum during the administration of personalized vitamin and mineral complex $\left(\left\langle{ }^{*}\right\rangle\right.$ - statistical value of differences to preliminary level is $p<0.05$ )

These trends, which consist in optimizing the crystallogenic properties of athletes' blood serum after a course of individualized metabolic correction, are reflected in the expression of the marginal zone as an indicator of the state of the proteome of the biosensor [4-6]. In this case, a significant expansion of the marginal zone of serum micro-preparations was observed (Fig. 4), which indicates an increase in the concentration of proteins with native configuration and physical and chemical properties $[6,12]$ and can be considered as a positive trend. In General, the data on the severity of the marginal zone of the biological fluid facias complement the positive picture of the response of the athletes' body metabolism to the conducted metabolic support, demonstrated by other estimated parameters of crystallization. They also fully fit into the functional and metabolic response to the studied effect, shown in our previous studies on the analysis of physical performance and the state of oxidative metabolism of the blood of the subjects. 


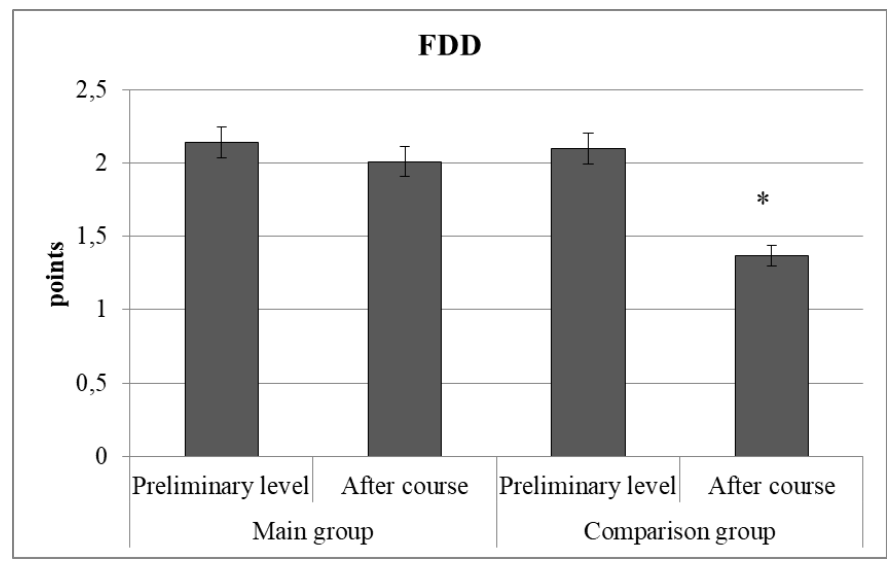

Figure 3. Destruction degree in facias of athletes blood serum during the administration of personalized vitamin and mineral complex $\left(«^{*} »-\right.$ statistical value of differences to preliminary level is $\mathrm{p}<0.05$ )

On the contrary, no significant deviations in the size and morphology of the marginal zone of facies were found in the representatives of the comparison group who received placebo (Fig. 4).

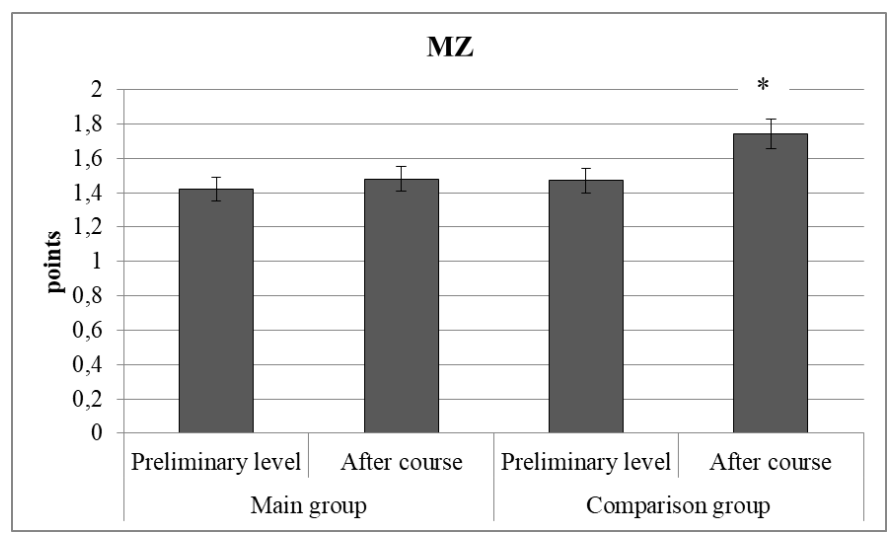

Figure 4. Clearity of marginal zone in facias of athletes blood serum during the administration of personalized vitamin and mineral complex $\left(\left\langle^{*}\right\rangle-\right.$ statistical value of differences to preliminary level is $\mathrm{p}<0.05$ )

This indicates that there is no psychogenic influence on the result of evaluating the effectiveness of the considered technology of individualized metabolic correction based on the parameters of crystallogenic activity of blood serum, which characterize both mineral and organic components of the latter.

\section{CONCLUSION}

In general, the study allowed us to establish that in qualified athletes, the course of taking biologically active agents, individualized on the basis of a multiparametric assessment of the state of oxidative metabolism of blood, contributed to the optimization of the crystallogenic properties of blood serum. This was manifested in the transformation of the structure of the main elements of the picture in the direction of reducing their size with a proportional increase in density, as well as in reducing the degree of destruction of crystals and expanding the marginal zone of the microslides.

The technology proposed by us, based on the study of the dynamics of the crystallogenic activity of athletes' blood serum, is universal and can be used to evaluate the effect of various options for pharmacological correction. It is known that the spectrum of such influences is quite wide [16-18], but the changes that form in the blood of the examined persons are nonspecific, which makes it possible to implement the technology regardless of the characteristics of the drug used.

\section{REFERENCES}

[1] L.A. Balykova, A.A. Shirokova, O.M. Soldatov "Using Lcarnitine to improve the adaptation of young athletes to physical load and the correction of stress-induced cardiomyopathy". Experimental and clinical pharmacology, vol. 77, no. 10, 19-25, 2014.

[2] R.S. Rakhmanov, L.V. Kuznetsova, T.V. Blinova et al. "Vitamin and mineral status of oarsmen during the training-competition cycles". Voprosy Pitaiya, vol. 82, no. 4, 76-81, 2013

[3] A.K. Martusevich, K.A. Karuzin, A.L. Larionov "Iron metabolism under selective individulized correction". Archiv Euromedica, vol. 9, no. 2, 72-73, 2019/

[4] G.M. Tinsley, A.J. Graybeal, M.L. Moore "Resting metabolic rate in muscular physique athletes: validity of existing methods and development of new prediction equations". Appl. Physiol. Nutr. Metab., vol. 44, no. 4, 397-406, 2019.

[5] B. Xu, Y. Zhang, Y. Chen et al. Simultaneous multielement analysis by ICP-MS with simple whole blood sample dilution and its application to uremic patients undergoing long-term hemodialysis". Scand. J. Clin. Lab. Invest., vol. 20, 1-9, 2020.

[6] K. Gawlik., A. Zwierzchowska, B. Rosołek "Evaluation of lipid metabolism and nutritional status in male goalball players". J. Hum. Kinet., vol. 48, 141-147, 2015.

[7] N.P. Stepanenko, T.E. Levitskaya, E.A. Tsekhmeistruk et al. "The comprehensive approach to the rehabilitative treatment of junior athletes". Vopr Kurortol Fizioter Lech Fiz Kult., vol. 94, no. 1, 46-50, 2017.

[8] E.A. Stacenko "Comparison of vitamine and mineral complexes for pharmacological support of antioxidant status of junior sportsman". Medical journal, no. 4, 109111,2007

[9] E.N. Trushina, V.D. Vybornov, N.A. Riger et al. "Immunomodulating effects of using L-carnitine and coenzyme Q10 in the nutrition of junior athletes". Voprosy Pitaiya., vol. 88, no. 2, 40-49, 2019.

[10] V.G. Zaitsev, O.V. Ostrovsky, V.I. Zakrevsky "Interaction between chemical composition and action target as basis of classification of direct antioxidants". Experimental and clinical pharmacology, vol. 66, no. 4, 66-70, 2003.

[11] I.A. Zborovskaya, M.V. Bannikova "Antioxidant system of organism, its role in metabolism. Clinical aspects". Gerald of Russian Academy of Medical Sciences, no. 6, 53-60, 1995. 
[12] S. Benedini, E. Dozio, P.L. Invernizzi et al. "Irisin: A potential link between physical exercise and metabolism an observational study in differently trained subjects, from elite athletes to sedentary people". J. Diabetes Res., 2017, $1039161,2017$.

[13] V.N. Kidalov, A.A. Khadartsev, G.N. Yakushina "Teziographic studies of the blood and its practice possibilities". Gerald of new medical technologies., vol. 11 , no. 1-2, 23-25, 2004.

[14] A.K. Martusevich, N.F. Kamakin "Crystallography of biological fluid as a method of evaluating its physicochemical characteristics". Bull. Exp. Biol. Med., vol. 143, no. 3, 385-388, 2007.

[15] Yu.Yu. Tarasevich "Mechanisms and models of dehydration self-organization of biological fluids". Uspekhi Physics, vol. 174, no. 7, 779-790, 2004.

[16] O.M.E. Abdel-Salam, E.R. Youness, A.A. Sleem. E.A. Omara "Oxidative Stress and Neuronal Injury After Cannabis and Ketamine Administration", WSEAS Transactions on Biology and Biomedicine, vol. 18, pp. 126-135, 2021.

[17] S.G. Dzugkoev, F.S. Dzugkoeva, O.I. Margieva, I.V. Mozhaeva, "Particition of Sodium-potassium Adenosine Triphosphatases in Homeostasis Regulation", WSEAS Transactions on Biology and Biomedicine, vol. 18, pp. 191-195, 2021.

[18]K. Prodanova "Optimizing Multiple Drug Administration from Depot by Applying Pharmacokinetic Concepts", WSEAS Transactions on Biology and Biomedicine, vol. 15, pp. 81-86, 2018.

\section{Contribution of Individual Authors to the Creation} of a Scientific Article (Ghostwriting Policy)

Andrew K. Martusevich: Conceptualization, Formal analysis and Writing - original draft.

Konstantin A. Karuzin: Investigation, Formal analysis and Writing - original draft and Writing - review \& editing.

Ivan V. Bocharin: Investigation, Formal analysis and Writing - original draft and Writing - review \& editing. Alexandra V. Surovegina: Investigation, Formal analysis and Writing - original draft \& editing.

\section{Creative Commons Attribution License 4.0 (Attribution 4.0 International, CC BY 4.0) \\ This article is published under the terms of the Creative Commons Attribution License 4.0 https://creativecommons.org/licenses/by/4.0/deed.en_US}

